\title{
The effect of parity on maternal body mass index, plasma mineral element status and new-born anthropometrics.
}

\author{
Emmanuel I. Ugwuja ${ }^{1,3}$, Richard C. Nnabu², Paul O. Ezeonu ${ }^{4}$, Henry Uro-Chukwu ${ }^{5}$
}

1. Departments of Chemical Pathology, Faculty of Clinical Medicine, Ebonyi State University, P.M.B. 053, Abakalik i, Nigeria

2. Department of Community Medicine, Federal Teaching Hospital Abakaliki, Nigeria

3. Department of Biochemistry, Faculty of Biological Sciences, Ebonyi State University, Abakaliki, Nigeria

4. Department of Obstetrics and Gynaecology, Federal Teaching Hospital Abakaliki, Ebonyi State, Nigeria

5. Department of Social Mobilisation and Disease Control, National Obstetric Fistula Centre, Abakaliki, Nigeria

\begin{abstract}
Background: Adverse pregnancy outcome is an important public health problem that has been partly associated with increasing maternal parity.

Aim: To determine the effect of parity on maternal body mass index (BMI), mineral element status and newborn anthropometrics.

Methods: Data for 349 pregnant women previously studied for the impacts of maternal plasma mineral element status on pregnancy and its outcomes was analysed. Obstetric and demographic data and $5 \mathrm{mls}$ of blood samples were obtained from each subject. Blood lead, plasma copper, iron and zinc were determined using atomic absorption spectrophotometer.

Results: Maternal BMI increases with parity. Women with parity two had significantly higher plasma zinc but lower plasma copper with comparable levels of the elements in nulliparous and higher parity groups. Although plasma iron was comparable among the groups, blood lead was significantly higher in parity $>$ three. Newborn birth length increases with parity with a positive correlation between parity and maternal BMI $(r=0.221 ; \mathrm{p}=0.001)$ and newborn birth length $(\mathrm{r}=0.170 ; \mathrm{p}=0.002)$ while plasma copper was negatively correlated with newborn's head circumference $(r=-0.115 ; p=0.040)$

Conclusion: It is plausible that parity affects maternal BMI and newborn anthropometrics through alterations in maternal plasma mineral element levels. While further studies are desired to confirm the present findings, there is need for pregnant and would-be pregnant women to diversify their diet to optimize their mineral element status.
\end{abstract}

Keywords: Maternal parity, BMI, newborn anthropometrics, mineral element status, pregnant women, Nigeria

DOI: http://dx.doi.org/10.4314/ahs.v15i3.37

Cite as: Ugwuja EI, Nnabu RC, Ezeonu PO, Uro-Chukwn H. The effect of parity on maternal body mass index, plasma mineral element status and new-born anthropometrics. Afri Health Sci. 2015;15(3):986-92. doi: http:/ / dx.doi.org/10.4314/ abs.v15i3.37

\section{Background}

Alterations in biochemical parameters, including essential minerals and vitamins during pregnancy are well documented ${ }^{1}$. These changes have been attributed to physiological, metabolic, psychological and hormonal changes that accompany pregnancy. The changes lead
Corresponding author:
Emmanuel I. Ugwuja,
Department of Chemical Pathology,
Faculty of Medicine, Ebonyi State University,
P.M.B. 053 Abakaliki, Nigeria
E-mail: ikeugwuja@gmail.com
Mobile phone: +2347035122010

to increased basal energy expenditure, reduced nutrient intakes, malabsorption, increased nutrient loss and metabolic alterations and expansion of plasma volume ${ }^{2}$.

For instance, several homeostatic adjustments in zinc metabolism during pregnancy and lactation have been suggested. These include alterations in intestinal zinc absorption, gastrointestinal secretion and renal conservation and release from maternal tissues ${ }^{3}$. Also, metabolism of copper, another essential trace element is known to be affected during pregnancy. In both human and animal studies maternal serum copper and ceruloplasmin concentrations have been found to increase throughout pregnancy ${ }^{4-7}$. It has recently been reported that parity-related changes in body weight and BMI influence zinc and copper status in urban pregnant women from South-Eastern Nigeria ${ }^{8}$. 
The physiological changes in pregnancy (expansion of plasma volume, increased erythropoiesis, and increased demand of the foetal unit for iron) occur throughout gestation and vary markedly between each individual ${ }^{9}$.

Studies have also reported alterations in blood lead during pregnancy. For example, increased maternal blood lead $(\mathrm{PbB})$ levels in pregnancy have been associated with increased nutritional demand and the homeorhesis associated with pregnancy. Mobilisation of lead from the bones has been found to be dependent on maternal age, overall nutritional status, parity and gestational $\operatorname{age}^{10}$.

Studies have documented that both deficiencies of essential trace elements, such as iron, copper and zinc and elevated blood level of lead are associated with adverse course and outcomes of pregnancy ${ }^{11-13}$. The complications of pregnancy induced by high blood lead level have been suggested to be through the alterations in trace element metabolism ${ }^{13}$. Although it is unequivocal that pregnancy is associated with alterations in essential minerals, it is yet to be clarified whether such changes are sustained after delivery. Again, except for the study of Singh et al. ${ }^{14}$, which reported increased level of blood lead and decreased levels of essential metals, which was associated with increased maternal parity, there is dearth of data on the effects of parity on maternal mineral status.

We hypothesise that if both biochemical and physiological alterations that occur in pregnancy are to be sustained after delivery, parity may have effect on newborn anthropometrics through such changes. Thus the present study aims to determine the effects of parity on maternal BMI, plasma levels of some mineral elements and foetal anthropometrics in a population of pregnant women in Abakaliki, South-East Nigeria.

\section{Materials and methods}

This prospective cohort study was part of a larger study carried out among pregnant women attending antenatal clinic of the Department of Obstetrics and Gynaecology of the Federal Medical Centre (now Federal Teaching Hospital), Abakaliki, one of the referral tertiary health institutions in the South Eastern part of Nigeria. The study area and subject selection have been previously described $^{15}$. Three hundred and fifty-one (351) women, aged $18-40$ years (Gestational age $\leq 25$ weeks), who gave their consent to participate in the study, were consecu- tively recruited between July 2007 and September 2008. The protocol for this study was approved by the Ethics and Research Committee of the hospital. The obstetric data of the participants was collected by structured questionnaires. Maternal anthropometry; height and weight were measured with the subject in light clothes without shoes, and BMI $\left(\mathrm{Kg} / \mathrm{m}^{2}\right)$ calculated. Five millilitres $(5.0 \mathrm{ml})$ of non-fasting venous blood collected between 08.00-10.00 hours were dispensed into trace element-free heparinised plastic bottles $(3.0 \mathrm{ml})$ and EDTA bottle $(2.0 \mathrm{ml})$ for determination of mineral elements and haematological parameters (packed cell volume (PCV) and haemoglobin concentration (HBC) and blood lead respectively.

While PCV and HBC were determined using standard haematological techniques and procedures as previously described $^{16}$, the blood samples in the trace element-free bottles were centrifuged at $2000 \mathrm{~g}$ for five minute for the isolation of plasma. The plasma samples were frozen until they were analysed. Plasma mineral elements were determined in duplicates using atomic absorption spectrophotometer and the mean was recorded as the absolute value of the elements.

As part of contamination control in blood lead $(\mathrm{Pb})$ determination, all glassware were routinely washed and soaked in two successive dilute nitric acid bathes ( 0.8 $\mathrm{mg} / \mathrm{l}$ ) and then thoroughly rinsed in ultra-pure double distilled deionized water. Additionally, all reagent, glassware and sample collection devices were checked for contamination with $\mathrm{Pb}$. No contamination was found when randomly selected sample of tubes used to collect and store blood for $\mathrm{Pb}$ assay were tested for $\mathrm{Pb}$. Briefly, the tubes were washed with $10 \%$ nitric acid (HNO3) and the effluent measured by atomic absorption spectrophotometer as described by Jacobson et al. ${ }^{17}$ for low $\mathrm{Pb}$ concentration. Certified lead reference solutions (obtained from Sigma-Aldrich Co LLC, USA) for atomic spectrometry were used as control.

Participants were followed up till after delivery. After delivery baby's anthropometrics, such as weight, length, and head circumference were recorded by the attending midwives. Baby's birth weight was determined using electronic weighing balance and recorded to the nearest $0.05 \mathrm{Kg}$ with the scale checked periodically throughout the study for accuracy while birth length and head circumference was determined by a measuring tape to the nearest $0.1 \mathrm{~cm}$. 


\section{Data analysis}

Basic statistical analyses were done employing one-way analysis of variance (ANOVA) and post-hoc multiple comparisons, where appropriate, to determine differences among means of parameters. Relationships among parameters were determined using Pearson correlation analysis. Values were expressed as mean and standard deviation. All statistical analyses were performed with SPSS ${ }^{\circledR}$ for Windows ${ }^{\circledR}$ version 16 and $\mathrm{p}$ values less than 0.05 were considered significant.

\section{Results}

Table 1 shows the general characteristics of pregnant women recruited at gestational age of $\leq 25$ weeks. Although 351 pregnant women were recruited, one $(0.3 \%)$ died early into the study, and of the remaining $350(99.7 \%)$ of which data was available samples were obtained from 349 participants as one participant declined participation. At delivery, data was available for $319(91.4 \%)$ women and their neonates. Data was incomplete or not available for the remaining 30 (8.6\%).

Table 1: General characteristics of participants

\begin{tabular}{llllll}
\hline Parameters & $\mathrm{n}$ & Minimum & Maximum & Mean & SD \\
\hline Maternal age (yrs) & 350 & 18 & 40 & 27.1 & 4.6 \\
Gestational age at recruitment (wks) & 350 & 11 & 25 & 21.8 & 3.1 \\
Parity $(\mathrm{n})$ & 350 & 0 & 9 & 1.64 & 2.0 \\
BMI $\left(\mathrm{Kg} / \mathrm{m}^{2}\right)$ & 350 & 17.8 & 42.6 & 27.3 & 4.3 \\
PCV $(\%)$ & 349 & 19 & 39 & 30.3 & 3.6 \\
Haemoglobin $(\mathrm{g} / \mathrm{dl})$ & 349 & 6.5 & 13.3 & 10.2 & 1.3 \\
Number of antenatal visit $(\mathrm{n})$ & 349 & 1 & 14 & 7.0 & 2.5 \\
Gestational age at delivery $(\mathrm{wks})$ & 319 & 33 & 43 & 39.1 & 1.7 \\
Plasma copper $(\mu \mathrm{mol} / \mathrm{L})$ & 349 & 0.89 & 45.36 & 9.59 & 9.41 \\
Plasma iron $(\mu \mathrm{mol} / \mathrm{L})$ & 349 & 1.79 & 45.12 & 10.24 & 7.69 \\
Plasma zinc $(\mu \mathrm{mol} / \mathrm{L})$ & 349 & 0.70 & 67.32 & 9.19 & 9.16 \\
Blood lead $(\mu \mathrm{mol} / \mathrm{dL})$ & 349 & 2.69 & 65.48 & 30.36 & 18.32 \\
\hline
\end{tabular}

SD: standard deviation; BMI: Body mass index; PCV: Packed cell volume

Although, generally the women were not deficient in any of the three trace elements evaluated (mean \pm SD of $9.59 \pm 9.42 \mu \mathrm{mol} / \mathrm{L}$ for copper, $10.25 \pm 7.69$ for iron, and $9.19 \pm 9.16$ for zinc), the ranges of the elements varied from very low levels to very high concentrations, with copper, iron and zinc concentrations ranging from 0.89 to $45.36,1.79$ to 45.12 and 0.70 to $67.32 \mu \mathrm{mol} / \mathrm{L}$, respectively. However, mean blood lead was found to be higher than the current CDC action limit $(>10 \mu \mathrm{g} / \mathrm{dL})$ and varied widely from $2.69-65.48 \mu \mathrm{g} / \mathrm{dL}$, with a mean of $30.36 \pm 18.32 \mu \mathrm{g} / \mathrm{dL}$.

Table 2 shows the effects of parity on BMI, haematological parameters, essential minerals status and blood lead of pregnant women. Parity had significant effects on maternal BMI, which increases with maternal parity, with least effect in nulliparity and maximum effect in the parity three. For the essential minerals, while parity two had significantly higher plasma zinc in comparison to other parity groups, the same group had significantly lower plasma copper when compared to other parity groups. However, comparable levels of copper and zinc were observed in lower parity group, nulliparity and higher parity groups.

While plasma iron was found to be comparable among the groups, blood lead was found to be significantly lower in parity two in comparison to parity zero and one, but was significantly higher in parity $>$ three. 
Table 2: Effects of parity on body mass index, haematological parameters, lead and some trace elements in a population of pregnant women in Abakaliki, Southeast Nigeria

\begin{tabular}{llllll}
\hline & \multicolumn{5}{c}{ Parity groups } \\
\cline { 2 - 6 } Parameters & $0(\mathrm{n}=140)$ & $1(\mathrm{n}=66)$ & $2(\mathrm{n}=53)$ & $3(\mathrm{n}=40)$ & $>3(\mathrm{n}=50)$ \\
\hline BMI $\left(\mathrm{Kg} / \mathrm{m}^{2}\right)$ & $26.2 \pm 3.9$ & $27.1 \pm 4.4$ & $28.1 \pm 5.0^{\dagger}$ & $29.4 \pm 3.8^{\dagger \dagger}$ & $28.0 \pm 3.8^{\dagger}$ \\
PCV $(\%)$ & $29.9 \pm 3.8$ & $31.0 \pm 3.8$ & $30.8 \pm 3.8$ & $30.0 \pm 2.1$ & $30.4 \pm 3.5$ \\
HBC $(\mathrm{g} / \mathrm{dl})$ & $10.1 \pm 1.3$ & $10.4 \pm 1.4$ & $10.4 \pm 1.3$ & $10.1 \pm 0.6$ & $10.2 \pm 1.2$ \\
Zinc $(\mu \mathrm{mol} / \mathrm{l})$ & $8.78 \pm 8.91$ & $8.73 \pm 8.10$ & $12.07 \pm 11.72^{\dagger \dagger}$ & $8.29 \pm 9.03^{\natural}$ & $8.58 \pm 7.94$ \\
Copper $(\mu \mathrm{mol} / 1)$ & $9.29 \pm 9.21$ & $10.96 \pm 10.68$ & $7.51 \pm 6.80^{\ddagger}$ & $9.51 \pm 9.10$ & $10.93 \pm 10.67$ \\
Iron $(\mu \mathrm{mol} / \mathrm{l})$ & $10.17 \pm 7.15$ & $9.71 \pm 8.24$ & $9.85 \pm 8.07$ & $9.76 \pm 5.16$ & $11.98 \pm 9.52$ \\
Lead $(\mu \mathrm{mol} / \mathrm{dl})$ & $29.75 \pm 18.04$ & $32.84 \pm 18.94$ & $26.80 \pm 17.38^{\ddagger}$ & $28.52 \pm 19.37$ & $34.01 \pm 18.08^{\natural}$ \\
\hline
\end{tabular}

BMI: Body mass index; PCV: Packed cell volume; HBC: Haemoglobin concentration;

Values are expressed as mean \pm standard deviation

$\dagger$ Significantly different from parity $0(\mathrm{p}<0.05)$

* Significantly different from parity $1(\mathrm{p}<0.05)$

" Significantly different from parity $2(\mathrm{p}<0.05)$

From table 3, parity had no significant effect on newborn birth weight, but there seemed to be increasing birth weight with increasing parity. Also, although newborn head circumference seemed to increase with increasing parity, the effect was not statistically significant. However, newborn birth length was found to be significantly $(\mathrm{p}<0.05)$ higher in parity three $(55.08 \pm 9.12 \mathrm{~cm})$ in comparison to other parity groups.
Partial correlation analysis, after controlling for age, gestational age and dietary intakes shows that parity was positively correlated with maternal BMI $(\mathrm{r}=0.221 ; \mathrm{p}=$ $0.001)$ and newborn birth length $(r=0.170 ; p=0.002)$. Also plasma copper was negatively correlated with newborn's head circumference $(r=-0.115 ; \mathrm{p}=0.040)$.

Table 3: Effects of parity on new-born anthropometrics

\begin{tabular}{llllll}
\hline & \multicolumn{5}{c}{ Parity groups } \\
\cline { 2 - 6 } Parameters & $0(\mathrm{n}=125)$ & $1(\mathrm{n}=60)$ & $2(\mathrm{n}=51)$ & $3(\mathrm{n}=37)$ & $>3(\mathrm{n}=46)$ \\
\hline $\mathrm{BW}(\mathrm{Kg})$ & $2.95 \pm 0.43$ & $3.04 \pm 0.51$ & $3.15 \pm 0.54$ & $3.15 \pm 0.57$ & $3.08 \pm 0.55$ \\
$\mathrm{BL}(\mathrm{cm})$ & $50.24 \pm 3.35$ & $50.15 \pm 3.24$ & $50.61 \pm 3.52$ & $55.08 \pm 9.12^{\dagger}$ & $50.87 \pm 3.33$ \\
$\mathrm{HC}(\mathrm{cm})$ & $33.71 \pm 2.51$ & $33.18 \pm 3.13$ & $33.43 \pm 2.63$ & $34.03 \pm 2.50$ & $34.07 \pm 2.67$ \\
\hline
\end{tabular}

BW: Birth weight; BL: Birth length; HC: Head circumference

${ }^{a}$ Values are mean \pm standard deviation.

$\dagger$ value significantly different $(\mathrm{p}<0.05)$ from other parity groups

\section{Discussion}

The wide variations in the levels of trace elements recorded in this study suggest a wide nutritional disparity among the women. Although the reason for this nutritional disparity remains obscure, contamination of water source may be a probability. Contamination of water supply has been found to be one of the important causes of acute toxicity of trace elements in the general population ${ }^{18}$. Another plausible contributory factor to the wide differences in concentrations of trace elements among these women is differential bioavailability of trace elements due to nutrient-nutrient interactions ${ }^{19,20}$. This has important public health implications not only for the mothers but also for their newborns as this may reflect in differential concentrations and availability of these elements to the foetus, which may ultimately affect maternal and foetal health. 
The study shows that maternal BMI significantly increased with parity, with women in parity two having significantly higher plasma zinc but lower plasma copper and lead respectively, while plasma iron was comparable among the groups. Blood lead was significantly higher in parity $>$ three. Again, parity had no significant effect on newborn birth weight, and head circumference but birth length was found to be significantly higher in parity three $(55.08 \pm 9.12 \mathrm{~cm})$ in comparison to other parity groups. Parity was positively correlated with maternal BMI $(r=0.221 ; p=0.000)$ and newborn birth length $(r$ $=0.170 ; \mathrm{p}=0.002)$ while plasma copper was negatively correlated with newborn head circumference.

Singh et $\mathrm{al}^{14}$ had previously reported that lead level increases with parity and this affects the essential metal levels, with maternal stores depleted with increasing parity. Again, studies ${ }^{21,22}$ have suggested depletion of maternal stores of essential elements with increasing parity. This is in corroboration with the present findings except for the rise in zinc in parity two, and for copper and iron in parity $>$ three. Although the reasons for these rises remain obscure, it suggests that these elements may have some homeostasis mechanism by which they maintain plasma levels when they are depleted beyond certain levels. For example, it has been found that fractional zinc absorption increased significantly in women with marginal zinc intakes during pregnancy and lactation, with increases higher in women with low plasma zinc ${ }^{23}$. Also, in a population with chronically low dietary zinc intake, conservation of endogenous zinc may be critical in the maintenance of zinc homeostasis than the adaptation in fractional absorption ${ }^{24}$. It remains to be ascertained whether the same homeostatic mechanisms apply for other essential elements.

The significantly higher blood lead in multiparous women (parity $>$ three) observed in the present study is in corroboration with previous findings ${ }^{25,26}$. Mirranda et al..$^{25}$ attributed this to increased bone resorption during pregnancy and more lead exposure on the average, for older women during childhood in comparison to younger mother. Increase in blood lead level with age has also been associated with continuous cumulative environmental exposure over time ${ }^{27}$. Similarly, the authors had previously reported higher prevalence of elevated blood lead in nulliparous and multiparous women in this population ${ }^{13}$, which they attributed to iron deficiency associated with multiparity. It has been shown that lead absorption is enhanced in iron deficiency state ${ }^{28}$. It may therefore be inferred that the elevated blood lead observed in the present study may rightly be associated with maternal anaemia, as anaemia was a significant finding among the women.

Like studies elsewhere ${ }^{29}$, in the present study, maternal haemoglobin and packed cell volume (PCV) decreases with maternal parity, which reaffirmed maternal depletion associated with increasing parity. In multiparous women, the space between successive pregnancies may not be long enough to allow for replenishment of lost blood and nutrients and this may partly explain the lower values of PCV and haemoglobin observed in the present study. Although we did not include the socioeconomic data of these women, multiparity has been associated with low socioeconomic class and multi-micronutrient deficiencies, which in turn have been associated with low haemoglobin and PCV, due to impairment of red blood cell synthesis ${ }^{30,31}$.

The positive correlation of maternal parity with BMI and newborn birth length observed in the present study is in accord with the findings of Nwagha et al. ${ }^{8}$, where pregnancy weight gain was found to be more pronounced in multiparous than in nulliparous women. The authors have also reported a positive relationship of maternal BMI with age, parity and socioeconomic status among pregnant Nigerians ${ }^{32}$ This may have important public health implications as adverse pregnancy outcomes have been associated with multiparity and increased maternal $\mathrm{BMI}^{33-35}$. It may be argued that the higher incidence of some pregnancy complications in high parous women, such as preterm delivery and macrosomia ${ }^{36,37}$ may be related to increase in maternal BMI. On the other hand, decreased maternal micronutrient levels, including essential elements may be a factor, as lowest plasma zinc had been reported in women with highest $\mathrm{BMI}^{38}$. Also, in addition to obesity, plasma zinc level has been found to be dependent on age, race and parity ${ }^{39}$, which is in corroboration with the present finding. The negative correlation between newborn head circumference and maternal plasma copper level suggests a relationship between newborn anthropometrics and maternal plasma mineral levels. Copper and zinc are essential elements, which play essential roles in several enzymes and transcription factors that regulate growth and development ${ }^{40,41}$. Both excesses and deficiencies of copper and zinc have been reported to have profound and sometimes, persistent effects on many foetal tissues and organs in the absence of clinical signs of deficiency 
in the mothers ${ }^{8}$. It may therefore be speculated that the parity related changes in maternal BMI observed in the present study may have impacted on newborn anthropometrics through the alterations in maternal plasma mineral levels. Although not empirically determined, the sample size (351), of the present study was high enough to detect significant difference where it truly existed. It is therefore a true representation of the population of the state and the findings may be generalized. It may therefore be concluded that increasing parity may affect maternal BMI and newborn anthropometrics through the alterations of maternal plasma mineral status. While further studies are desired to confirm the present findings, pregnant and would-be pregnant women should be encouraged to diversify their diet to optimize their mineral element status.

\section{Acknowledgement}

The authors are grateful to staff members of Obstetrics and Gynaecology Department for logistic support.

\section{References}

1. Hininger I, Favier M, Arnaud J, et al. Effects of a combined micronutrient supplementation on maternal biological status and newborn anthropometrics measurements: a randomised double-blind, placebo-controlled trial in apparently healthy pregnant women. Eur J of Clin Nutr 2004; 58: 5259.

2. Allen LH. Multiple micronutrients in pregnancy and lactation: an overview. Am J Clin Nutr 2005; 81: 1206S-1212S.

3. King J C. Determinants of maternal zinc status during pregnancy. Am J Clin Nutr 2000; 71 (Supp 1): 1334S-1343S.

4. Linder, M. The biochemistry of copper. New York: Plenum Press; 1991.

5. Krachler M, Rossipal E and Micetic-Turk D. Trace element transfer from mother to the new born-investigations on triplets of colostrums, maternal and umbilical cord sera. Eur J Clin Nutr 1991; 53: 486-494.

6. Khan MN, Ashraf M, Salam A, et al. Maternal serum copper level; evaluation in normal gravidae in relation to course and advancement of human pregnancy. The Professional 2001; 8: 387-389.

7. Upadhyaya C, Mishra S, Ajmera P and Sharma P. Serum iron, copper and zinc status in maternal and cord blood. Ind J Clin Biochem 2004; 19: 48-52.

8. Nwangha UI, Iyare EE, Ogbodo, et al. Parity-relat- ed changes in body weight may influence the zinc and copper status of urban pregnant women: A report from south eastern Nigeria. J Basic and Clin Reproductive Sci 2013; 2: 32-37.

9. van den Broek, N. Anaemia and micronutrient deficiencies. Br Med Bull 2003, 67: 149-160

10. Bellinger, D. Teratogen update: Pb. Teratology 1994; 50: 367-73.

11. Ugwuja EI, Akubugwo EI, Ibiam UA, et al. Plasma Copper and Zinc among Pregnant Women in Abakaliki, Southeastern Nigeria. The Internet Journal of Nutrition and Wellness 2010; 10:1

12. Ugwuja EI, Akubugwo EI, Ibiam UA and Obidoa O. Impact of Maternal Iron Deficiency and Anaemia on Pregnancy and its outcomes in a Nigerian Population. The Internet Journal of Nutrition and Wellness 2010; $10: 1$.

13. Ugwuja EI, Ejikeme B. and Obuna JA. Impacts of elevated prenatal blood lead on trace element status and pregnancy outcomes in occupationally non-exposed women. Intern J Occupat Environ Med 2011; 2: 143-156.

14. Singh J, Singh VK, Anand M, et al. Placental lead and its interaction with some essential metals among women from Lucknow, India. Asian J Med Sci 2010; 1: 32-36.

15. Ugwuja EI, Akubugwo EI, Ibiam UA and Obidoa O. Impact of Maternal Copper and Zinc Status on Pregnancy Outcomes in a Population of Pregnant Nigerians. Pak J Nutr 2010; 9: 678-682.

16. Dacie JV and Lewis SM.Practical Haematology, 8th ed. Edinburg, Churchill Livingstone, 1994; 49-59.

17. Jacobson BE, Lokltch $\mathrm{O}$ and Qulgley GC. Improve sample preparation for accurate determination of low concentration of $\mathrm{Pb}$ in whole blood by graphite furnace analysis. Clin Chem 1991; 37: 515-519.

18. Bremner I. Manifestations of copper excess. Am J Clin Nutr 1998; 67:1069S-73S.

19. Sandstrom B. Micronutrient interactions: effects on absorption and bioavailability. Br J Nutr 2001;85 :S181-S5.

20. Turnlund JR. Copper. In: Shils ME, Shike M, Ross AC, et al, eds. Modern Nutrition in Health and Disease. 10th ed. Philadelphia, Lippincott Williams \& Wilkins, 2006:286-99.

21. Osman K, Akesson A, Berglund M, et al. Toxic and essential elements in placentas of Swedish women. Clin Biochem 2000, 33: 131-8.

22. Akesson A, Bjellerup P, Berglund M, et al. Serum transferin receptor: a specific marker of iron deficiency in pregnancy. Am J Clin Nutr 1998; 68: 1241-6. 
23. Donangelo CM, Zapata CL, Woodhouse LR, et al. Zinc absorption and kinetics during pregnancy and lactation in Brazilian women. Am J Clin Nutr 2005; 82: 118-24.

24. Sian L, Mingyan X, Miller LV, et al. Zinc absorption and intestinal losses of endogenous zinc in young Chinese women with marginal zinc intakes. Am J Clin Nutr 1996; 63: 348-353.

25. Miranda ML, Edwards SE, Swamy GK, et al. Blood $\mathrm{Pb}$ levels among pregnant women: historic versus contemporaneous exposure. Int J Environ Res Public Health 2010; 7: 1508-1519.

26. Hertz-Picciotto I, Schramm M, Watt-Morse M, et al. Patterns and determinants of blood $\mathrm{Pb}$ during pregnancy. Am J Epidemiol 2000; 152: 829-37.

27. Jain RB. Effect of Pregnancy on the Levels of Blood Cadmium, Lead, and Mercury for Females Aged 17-39 Years Old: Data from National Health and $\mathrm{Nu}-$ trition Examination Survey 2003-2010. Journal of Toxicology and Environmental Health, Part A 2013; 76: 58-69.

28. Jin C, Li YL, Zou Y, et al. Blood lead: its effect on trace element levels and iron structure in haemoglobin. Nuclear Instruments and Methods in Physics Research Section B: Beam Interactions with Material and Atoms 2008; 266: 3607-13.

29. Danish HQ, Mohammad PS, Tahseen K, et al. Influence of maternal factors on haematological parameters of healthy newborns of Karachi. PakJ Physiol 2009; 5: 34-37.

30. Noronha JA, Bhaduri A, Vinod Bhat H, et al. Maternal risk factors and anaemia in pregnancy: a prospective retrospective cohort study. J Obstet Gynaecol 2010; 30:132-6.

31. Hieu NT, Sandalinas F, de Sesmaisons A, et al. Multi-micronutrient-fortified biscuits decreased the prevalence of anaemia and improved iron status, whereas weekly iron supplementation only improved iron status in Vietnamese school children. Br J Nutr. 2012; 108:1419-27.
32. Ugwuja, E. I., Akubugwo, E. I., Ibiam, U. A. and Obidoa, O. Maternal BMI during Pregnancy: Impacts on trace elements status and pregnancy outcomes. International Journal of Health Research 2010; 3(2): 71-78.

33. Waller DK, Shaw GM, Rasmussen SA, et al. National Birth Defects Prevention Study. Prepregnancy obesity as a risk factor for structural birth defects. Arch Pediatr Adolesc Med. 2007; 161:745-50.

34. Stothard KJ, Tennant PW, Bell R and Rankin J. Maternal overweight and obesity and the risk of congenital anomalies: a systematic review and meta-analysis. JAMA 2009; 301:636-50.

35. Poobalan AS, Aucott LS, Gurung T, et al. Obesity as an independent risk factor for elective and emergency caesarean delivery in nulliparous women--systematic review and meta-analysis of cohort studies. Obes Rev 2009; 10:28-35.

36. Shaikh K, Premji SS, Rose MS, et al. The association between parity, infant gender, higher level of paternal education and preterm birth in Pakistan: a cohort study. BMC Pregnancy and Childbirth 2011; 11:88.

37. Aliyu MH, Salihu HM, Keith LG, et al. High parity and fetal morbidity outcomes. Obstet Gynaecol. 2005; 105:1045-1051.

38. Tamura T, Goldenberg RL, Kelley EJ and Chapman VR. Relationship between pre-pregnancy BMI and plasma zinc concentration in early pregnancy. Br J Nutr 2004, 91: 773-777.

39. Neggers Y, Goldenberg RL, Clive SP, et al. The relationship between maternal and neonatal anthropometric measurements in tern newborns. Obstet Gynaecol 1995; 85: 192-196.

40. Ozdemir U, Gulturk S, Akar A, Guvenal T, Imir G and Erselcan T. Correlation between birth weight, leptin, zinc and copper levels in maternal and cord blood. J Physiol Biochem 2007; 63: 121-8.

41. Hossain KJ, Kamal MM, Ahsan M, Islam SN. Serum antioxidant microminerals $(\mathrm{Cu}, \mathrm{Zn}, \mathrm{Fe})$ status of drug-dependent subjects: influenceof illicit drugs and lifestyle. Subst Abuse Treat Prev Policy 2007; 2: 12. 